\title{
Phenolic extracts of coconut oil cake: a potential alternative for synthetic antioxidants
}

\author{
Kapila Nalawatta SENEVIRATNE ${ }^{1 *}$, Withanage Chaturi PRASADANI ${ }^{1}$, Bimali JAYAWARDENA ${ }^{1}$
}

\begin{abstract}
Limitations of natural antioxidants include relatively low antioxidant activity, narrow range of food systems where the antioxidants are effective and limited thermal stability compared to synthetic antioxidants. In the present study, the phenolic extract of coconut oil cake (COCE) was tested for antioxidant activity-related food stabilization. Heat stabilities of COCE and synthetic antioxidants were determined by measuring the induction time of sunflower oil enriched with heat-treated antioxidants. In the $\beta$-carotene-linoleate emulsion used for testing antioxidant activity, COCE can retain $96 \pm 2 \%$ of initial colour intensity while BHT can retain $89 \pm 2 \%$ of initial colour intensity at $60 \mu \mathrm{g} \mathrm{mL}^{-1}$ concentration after two hours. TBARS contents (MDA equivalents / $\mathrm{kg}$ of meat) in COCE-treated and control pork samples after 14 days was $2.80 \pm 0.57$ and $22.55 \pm 2.30$ respectively. Heat stability varies in the order butylated hydroxytoluene $(\mathrm{BHT})<$ (butylated hydroxyanisole $(\mathrm{BHA})<\mathrm{COCE}<$ tertiary butylhydroxyquinone (TBHQ). The results of these experiments suggest that COCE is a versatile and thermally stable natural antioxidant mixture effective in stabilizing many food systems.
\end{abstract}

Keywords: coconut oil cake; antioxidants; polyphenols; DPPH; food model systems.

Practical Application: Ethanolic extracts of coconut oil cake can improve the shelf life of food emulsions, meat and polyunsaturated oils. Phenolic antioxidants responsible for these food stabilizing effects are highly thermally stable. Therefore, the extracts of coconut cake can be developed as commercial natural antioxidant preparations with potential applications in food industry.

\section{Introduction}

Lipid peroxidation is one of the major reasons for the deterioration of food during processing and storage. Synthetic antioxidants such as butylated hydroxyanisole (BHA) and butylated hydroxytoluene (BHT) are common synthetic antioxidants used in food stabilization. However, use of synthetic antioxidants has been restricted by many countries due to the possible carcinogenicity of these compounds. BHA and BHT are known to be carcinogenic in some organisms (Ito et al., 1985; Thamavit et al., 1989; Ito \& Hirose, 1989). Use of BHA and BHT is also limited because of the high volatility and decomposition of these compounds at high temperatures. BHA, BHT and tert-butylhydroquinone (TBHQ) decompose below $180^{\circ} \mathrm{C}$ and therefore their protective effect on vegetable oils undergoing frying process is very little (Reda, 2011).

Consumers of organic foods prefer natural antioxidants as stabilizers of their foods. Rosemary and sage extracts are well-known natural antioxidants which are available in commercial scale as food stabilizers. Rosemary and sage extracts have been proven to be effective in lowering the rate of oxidation of oils during frying at about $180^{\circ} \mathrm{C}$ (Che Man \& Jaswir, 2000). A combination of rosemary extract, sage extract and citric acid retained the fatty acid C18:2 during deep fat frying. Rosemary extracts also improved oxidative stability and supported retaining tocopherols in soybean oil at high temperatures (Casarotti \& Jorge, 2014).
A synergistic effect among these antioxidants on the C18:2/C16:0 fatty acid ratio of RBD palm olein was found (Jaswir et al., 2000). Among the natural antioxidants, vitamin $\mathrm{C}$ is one of the least heat-stable of all vitamins in solution. Tocopherols are also destroyed under cooking conditions. $\alpha$ - and $\gamma$-tochopherol in row corn was totally destroyed when corn was processed into tortillas (Wyatt et al., 1998). Vitamin E content in milled barely decreased by $5 \%$ per week at room temperature and at $120^{\circ} \mathrm{C}$, vitamin $\mathrm{E}$ content reduced to $8 \%$ of the initial value after $24 \mathrm{~h}$ (Tyopponen \& Hakkarainen, 1985). Phenolic compounds including phenolic acids and flavonoids seem to be more stable than other vitamin antioxidants in food systems under processing and storage conditions (Seneviratne et al., 2009).

Oil cakes or oil meals are by-products obtained after oil extraction from various seeds. In addition to their use as animal food, oil cakes have been used for the fermentative production of enzymes, antibiotics and some antioxidants (Ramachandran et al., 2004). However, there are no reports of the utilization of coconut oil cake (COC) as a direct source of antioxidants. In the production of one metric ton of coconut oil, half a ton of COC is produced. Therefore, the annual production of COC is 1.72 million metric tons (United States Department of Agriculture, 2015). The present study was conducted to evaluate the potential of $\mathrm{COC}$ as a source of antioxidants to 
stabilize foods with the ultimate goal of producing coconut oil cake-based natural antioxidant preparations with commercial applications in food industries.

\section{Materials and methods}

\subsection{Chemicals}

Authentic standards for HPLC analysis, 1,1-diphenyl-2picrylhydrazyl (DPPH), BHA, BHT and TBHQ were purchased from Sigma (St. Louis, MO). All other chemicals were purchased from either Sigma or Fluka (Buchs, Switzerland).

\section{$2.2 \mathrm{COC}$}

Fresh COC produced as a by-product of the extraction coconut oil by a small-scale expeller commonly used in coconut oil industries was used for the experiments. COC was ground using a kitchen grinder, sieved through a $180 \mu \mathrm{m}$ mesh, dried at $40^{\circ} \mathrm{C}$ until a constant weight was obtained (usually $24 \mathrm{~h}$ ) and stored at $-20^{\circ} \mathrm{C}$.

\subsection{Preparation of COCE}

Ethanol/water $(70: 30 \mathrm{v} / \mathrm{v}, 10 \mathrm{~mL})$ was mixed with COC $(10.0 \mathrm{~g})$ and the mixture was agitated using a vortex at $40 \mathrm{~Hz}$ for $2 \mathrm{~min}$ (twice). The mixture was centrifuged (1080 g, $10 \mathrm{~min}$ ) and the resultant clear solution was separated. This procedure was repeated 4 times for the same COC sample with fresh $10 \mathrm{~mL}$ portions of the solvent system. The resultant extracts were collected, diluted to $50.0 \mathrm{~mL}$ and stored in a dark brown vial under nitrogen until further experiments were carried out.

\subsection{Total phenol content}

Total phenol contents (TPC) of COCE were determined by the Folin-Denis method. The Folin-Denis reagent was prepared by the method of Perry et al. (2001). Appropriately diluted COCE $(1.0 \mathrm{~mL})$ was used with Folin-Dennis reagent $(1.0 \mathrm{~mL})$ for this evaluation. A calibration curve was plotted using gallic acid as the standard. Different concentrations of COCE for all the experiments were prepared by suitable dilutions based on the total phenol contents.

\subsection{DPPH radical-scavenging activity}

DPPH radical scavenging activity of COCE was measured according to the method reported by Hatano et al. (1988). Each COCE aliquot $(50 \mu \mathrm{L})$ of various concentrations $\left(20,40,60\right.$ and $\left.80 \mu \mathrm{g} \mathrm{mL}^{-1}\right)$ was added to a methanolic solution of DPPH ( $0.3 \mathrm{~mL}, 0.8 \mathrm{mM})$, total volume was adjusted to $3.0 \mathrm{~mL}$ with methanol and the resultant mixture was vortexed at $40 \mathrm{~Hz}$ for $5 \mathrm{~min}$. After $30 \mathrm{~min}$ of incubation at room temperature in the dark, the absorbance of each mixture was measured at $517 \mathrm{~nm}$. The DPPH radical scavenging activity was measured similarly for a series of $20-80 \mu \mathrm{g} \mathrm{mL}^{-1}$ solutions of BHT.

\subsection{Bleaching of $\beta$-carotene-linoleic acid emulsion}

The antioxidant activity was evaluated in a $\beta$-carotene-linoleate model system as explained by Wettasinghe \& Shahidi (1999). Required amounts of COCE or BHT were introduced in an ethnolic solution $(20 \mu \mathrm{L})$ to prepare $15,30,60 \mu \mathrm{g} \mathrm{mL} \mathrm{L}^{-1} \mathrm{COCE}$ or BHT concentrations in $\beta$-carotene - linoleic acid emulsion. Control solution was prepared by adding $70 \%$ ethanol $(20 \mu \mathrm{L})$ in the place of phenolic extract. The absorbance of each solution was read at $450 \mathrm{~nm}$ at $30 \mathrm{~min}$ intervals for $120 \mathrm{~min}$ starting at 0 min using a microplate reader (Thermo Scientific, Multiskan GO, Vantana, Finland). A solution with all the components except $\beta$-carotene was used for the background subtraction of absorbance.

\subsection{Lipid oxidation in egg yolk homogenates}

The method of Kuppusamy et al. (2002) was used to determine the thiobarbituric acid reactive substances (TBARS), as secondary products of lipid peroxidation. A $25 \mathrm{~g} \mathrm{~L}^{-1}$ egg yolk emulsion was prepared in $0.1 \mathrm{M}$ phosphate buffer ( $\mathrm{pH}$ 7.4). To prepare egg yolk emulsions with appropriate phenolic concentrations, egg yolk emulsion $(1 \mathrm{~mL})$ was mixed with $\mathrm{Fe}^{2+}$ solution $(100 \mu \mathrm{L}, 1000 \mu \mathrm{M})$ in each $5 \mathrm{~mL}$ Pyrex reaction tube. Then required volumes of COCE to achieve $0.125-16 \mu \mathrm{g} \mathrm{mL}^{-1}$ phenolic concentrations in the reaction tubes were added and the total volume of each mixture was adjusted to $1.5 \mathrm{~mL}$ with ethanol:water $(70: 30 \mathrm{v} / \mathrm{v})$. The mixtures were incubated at $37^{\circ} \mathrm{C}$ for $1 \mathrm{hr}$. Then each incubated mixture was treated with freshly prepared TCA $(0.5 \mathrm{~mL}, 15 \% \mathrm{w} / \mathrm{v})$ and thiobarbituric acid $(1.0 \mathrm{~mL}, 1 \%)$. The reaction tubes were kept in a boiling water bath for $10 \mathrm{~min}$. The contents of the tubes were cooled to room temperature and centrifuged ( $3500 \mathrm{~g}, 10 \mathrm{~min}$ ). The formation of TBARS was monitored by removing $300 \mu \mathrm{L}$ of supernatant from each tube and measuring the absorbance at $532 \mathrm{~nm}$. The buffered egg yolk emulsion without added phenolic extract or BHT was used as the control.

\subsection{Lipid oxidation in cooked pork}

Cooked pork samples for the analysis was prepared according to the method of Wijeratne et al. (2006) with COCE, BHT and TBHQ at $200 \mu \mathrm{g} / \mathrm{g}$ in pork. Samples of $2.0 \mathrm{~g}$ cooked pork were transferred to polythene bags. These samples were stored in a refrigerator at $4{ }^{\circ} \mathrm{C}$ and samples were used to analyze TBARS levels after $0,5,7$, and 14-day periods. The control experiment was carried out similarly with no added antioxidants in pork. Analysis of the TBARS levels was done according to the method described by Siu and Draper, (1978).

\subsection{Thermal stability of COCE using egg yolk homogenates}

BHA, BHT, COCE and TBHQ (100 $\mu$ g each) were separately transferred to $5 \mathrm{~mL}$ pyrex tubes and the contents were heated in an oven maintained at $180^{\circ} \mathrm{C}$. Tubes were taken out from the oven at each $30 \mathrm{~min}$ interval for $120 \mathrm{~min}$, cooled to room temperature and the contents were dissolved in $400 \mu \mathrm{L}$ of the solvent system (ethanol: water 70:30 v/v). To each solution, egg yolk emulsion prepared as above $(1.0 \mathrm{~mL})$ and $\mathrm{Fe}^{2+}$ solution $(100 \mu \mathrm{L}, 1000 \mu \mathrm{M})$ were added and mixture was incubated at $37^{\circ} \mathrm{C}$ for $1 \mathrm{~h}$. TBARS levels were measured in the sample as described above.

\subsection{Thermal stability of COCE using Rancimat test}

Quantities of BHA, BHT, COCE and TBHQ required to obtain $200 \mathrm{\mu g} \mathrm{g}^{-1}$ oil was transferred to the reaction tubes of the Rancimat apparatus (892 Professional Rancimat, Metrohm Swistzerland) and the contents of the tubes were heated in an oven at $180^{\circ} \mathrm{C}$ 
for $120 \mathrm{~min}$. The tubes were then cooled to room temperature and stripped sunflower oil (3.2 g) was added to each tube and vortexed ( $40 \mathrm{~Hz}, 2 \mathrm{~min}$ ). The induction time (IT) of the oils in the tubes were determined at $100{ }^{\circ} \mathrm{C}$ using Rancimat apparatus. Stripped sunflower oil (3.2 g) without added antioxidants was used as the control. Results of the antioxidant added oils were also reported as protection factor $(\mathrm{PF}): \mathrm{PF}=$ [IT (antioxidant added oil) / IT (control)].

\subsection{Identification and quantification of phenolic compounds in COCE}

COCE was purified according to the procedure described by Montedoro et al. (1992). HPLC method used is based on the reported procedures (Seneviratne \& Dissanayake, 2008; Seneviratne \& Kotuwegedara, 2009). HPLC experiments were performed using an Agilent 1100 Infinity Liquid Chromatographic System (Agilent Technologies, Waldbronn, Germany) equipped with an Agilent 1200 diode array detector. A ZORBAX ECLIPSE Plus C18 column (Agilent Technologies, USA) $(4.6 \mathrm{~mm} \times 100 \mathrm{~mm} \times 3.5 \mu \mathrm{m}$ particle size $)$ maintained at room temperature was used for this purpose. The mobile phase consisted of $1 \times 10^{-3} \mathrm{M} \mathrm{H}_{2} \mathrm{SO}_{4}$ in deionised water (A) and methanol (B). The total running time was $40 \mathrm{~min}$ with a flow

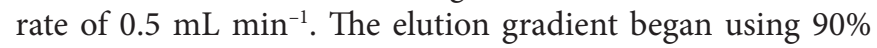
$\mathrm{A} / 10 \% \mathrm{~B}$ and this solvent composition was continued for $10 \mathrm{~min}$. The solvent $\mathrm{B}$ was increased to $55 \%$ from 10 to $20 \mathrm{~min}$ and this composition (45\% A/55\% B) was continued for 20-30 min. From 30 to $35 \mathrm{~min}$, solvent B was increased to $80 \%$ and this composition (20\% A and $80 \%$ B) was continued for 35-40 min. Sample $(20 \mu \mathrm{L})$ was injected into the HPLC system. Authentic phenolic standards and phenolic compounds in COCE were detected at a wavelength of $280 \mathrm{~nm}$. Phenolic compounds of COCE were identified by careful comparison of retentions times of the signals with those of authentic phenolic standards. The presence of identified phenolic substances and the absence of ascorbic acid were further confirmed by spiking COCE with relevant authentic standards Phenolic compounds were quantified by a previously reported method (Seneviratne \& Dissanayake, 2008). Standard curves for quantitative analysis were plotted using the known concentrations of the authentic standards of identified phenolic compounds. Data were stored and processed with Agilent Chemstation software.

\subsection{Statistical analysis}

All analyses were run in triplicate unless otherwise indicated. Tukey's pairwise test was carried out after ANOVA for the determination of significant differences $(p<0.05)$ between the means. Data were analysed using Minitab Version 17 for Windows (Pennsylvania State University, USA).

\section{Results and discussion}

\subsection{Total phenol content and DPPH radical scavenging activity}

Phenolic antioxidants from natural sources can be successfully extracted using acetone and methanol solvents (Andrade et al., 2015). However, for human consumption purposes, ethanol is considered as the safest solvent and the phenolic mixtures extracted using $70 \%$ ethanol have shown the highest oxygen radical absorbance capacity compared to the phenolic mixtures extracted using other commonly used solvent systems (Xu \& Chang, 2007). TPC ( $\left.\mathrm{mg} \mathrm{kg}^{-1}\right)$ as gallic acid equivalents of COC extracts is $2557 \pm 55$. A significant variation in the TPC of the samples were not observed based on the sampling time or location. DPPH radical scavenging activity was determined for BHT and COCE as a preliminary step to evaluate the antioxidant potential of COCE compared to the synthetic antioxidants. The results are given in the Table 1 . There was no significant difference in the DPPH radical scavenging activities of BHT and COCE at $20-60 \mu \mathrm{g} \mathrm{mL} \mathrm{m}^{-1}$ range, as reflected by percentage inhibition. DPPH radical scavenging activity is significantly higher at $80 \mu \mathrm{g} \mathrm{mL} \mathrm{m}^{-1}$ for COCE.

\subsection{Bleaching of $\beta$-Carotene colour}

Inhibition of the oxidative deterioration of plant pigments such as anthocyanin by phenolic antioxidants is important to preserve the nutritional quality and the colour of fruit juices (Roidoung et al., 2016). The potential of phenolic antioxidants to inhibit bleaching of the colour of pigments such as $\beta$-carotene can also be used to evaluate the antioxidant potential of phenolic substances. $\beta$-Carotene is a molecule with highly conjugated double bonds. Systems with less conjugated double bonds absorb energy from UV region for electronic transitions and such compounds are colourless to human eye. However, $\beta$-carotene with 11 conjugated double bonds absorb energy from the visible range to give a strong orange colour, which fades with the disturbance of conjugation due to the oxidation of $\beta$-carotene by the peroxy radicals generated in linoleic acid. Antioxidants inhibit the formation of peroxy radicals, thereby inhibiting the oxidation of $\beta$-carotene. Both $\mathrm{BHT}$ and COCE can inhibit bleaching of $\beta$-carotene colour at all concentrations tested $(15-60 \mu \mathrm{g} / \mathrm{mL}$ ) (Figure 1a). The inhibitory effect is concentration-dependent and varies in the order: COCE $60 \mu \mathrm{g} \mathrm{mL} \mathrm{m}^{-1}>$ COCE $30 \mu \mathrm{g} \mathrm{mL} L^{-1}>$ BHT $60 \mu \mathrm{g} \mathrm{mL}^{-1}>$ BHT $30 \mu \mathrm{g} \mathrm{mL}^{-1}>$ BHT $15 \mu \mathrm{g} \mathrm{mL} \mathrm{m}^{-1}>$ COCE $15 \mu \mathrm{g} \mathrm{mL}{ }^{-1}$. After two hours, COCE can retain $79 \pm 1 \%, 94 \pm 4 \%$ and $96 \pm 2 \%$ of initial colour intensity at 15,30 and $60 \mu \mathrm{g} \mathrm{mL} \mathrm{m}^{-1}$ concentrations respectively while $\mathrm{BHT}$ can retain $88 \pm 2 \%, 88 \pm 3 \%$ and $89 \pm 2 \%$ of initial colour intensity at 15,30 and $60 \mu \mathrm{g} \mathrm{mL}^{-1}$ concentrations respectively. Control could retain $40 \pm 1 \%$ of the initial colour after two hours. The results also show that COCE is more effective in inhibiting the bleaching of $\beta$-carotene colour within 30-60 $\mu \mathrm{g} \mathrm{mL} \mathrm{mL}^{-1}$ range compared to $\mathrm{BHT}$ within the same range. According to Codex Alimentarius (World Health Organization, 2001), maximum permissible concentration of BHT in food

Table 1. DPPH radical scavenging activity of BHT and coconut oil cake extracts (COCE).

\begin{tabular}{|c|c|c|c|c|c|}
\hline \multicolumn{2}{|c|}{$\begin{array}{l}\text { Phenolic concentration } \\
(\mu \mathrm{g} / \mathrm{mL})^{*}\end{array}$} & 20 & 40 & 60 & 80 \\
\hline DPPH Assay & COCE & $28 \pm 2^{\mathrm{a}}$ & $37 \pm 2^{\mathrm{a}}$ & $43 \pm 1^{a}$ & $51 \pm 2^{\mathrm{a}}$ \\
\hline Inhibition (\%) & $\mathrm{BHT}$ & $31 \pm 1^{\mathrm{a}}$ & $37 \pm 3^{\mathrm{a}}$ & $41 \pm 2^{\mathrm{a}}$ & $44 \pm 0^{\mathrm{b}}$ \\
\hline
\end{tabular}


systems is $200 \mathrm{ppm}$. Both BHT and COCE show their maximum efficiency of antioxidant activity at concentrations well below 200 ppm.

\subsection{Lipid peroxidation in egg yolk homogenates}

Egg yolk homogenates can be considered as an excellent lipid-rich emulsion food model for the evaluation of lipid peroxidation. Egg yolk mainly contains lipids, proteins carbohydrates and cholesterol. The major polyunsaturated fatty acid present in egg yolk is linoleic acid. In addition, egg yolk also contains palmitoleic acid and linolenic acid. These polyunsaturated lipids undergo lipid peroxidation which leads to the formation of secondary oxidation products such as TBARS which can be quantified colourimetrically using malondialdehyde as the standard compound. Usually these peroxidation reactions have to be induced by ferrous $\left(\mathrm{Fe}^{2+}\right)$ ions. The $\mathrm{EC}_{50}$ values obtained for BHT and COCE are $2.77 \pm 0.43 \mu \mathrm{g} \mathrm{mL}^{-1}$ and $6.46 \pm 0.10 \mu \mathrm{g} \mathrm{mL}^{-1}$ respectively. However, the inhibition percentages by COCE and BHT at concentrations $12.00 \mu \mathrm{g} \mathrm{mL}^{-1}$ and above are closely comparable according to the Figure $1 \mathrm{~b}$. $\mathrm{EC}_{50}$ values have been reported for the methanolic extracts of fermented maize $\left(6.00 \mathrm{mg} \mathrm{L}^{-1}\right)$ and unfermented maize $\left(8.25 \mathrm{mg} \mathrm{L}^{-1}\right)$ while catechin showed an $\mathrm{EC}_{50}$ value of $0.225 \mathrm{mg} \mathrm{L}^{-1}$ in the same egg yolk homogenate system (Daker et al., 2008). Percentage inhibition of the lipid peroxidation of COCE at $8.00 \mathrm{mg} \mathrm{L}^{-1}$ and $12.00 \mathrm{mg} \mathrm{L}^{-1}$ concentrations is $63.0 \pm 3.5$ and $73.8 \pm 1.5$
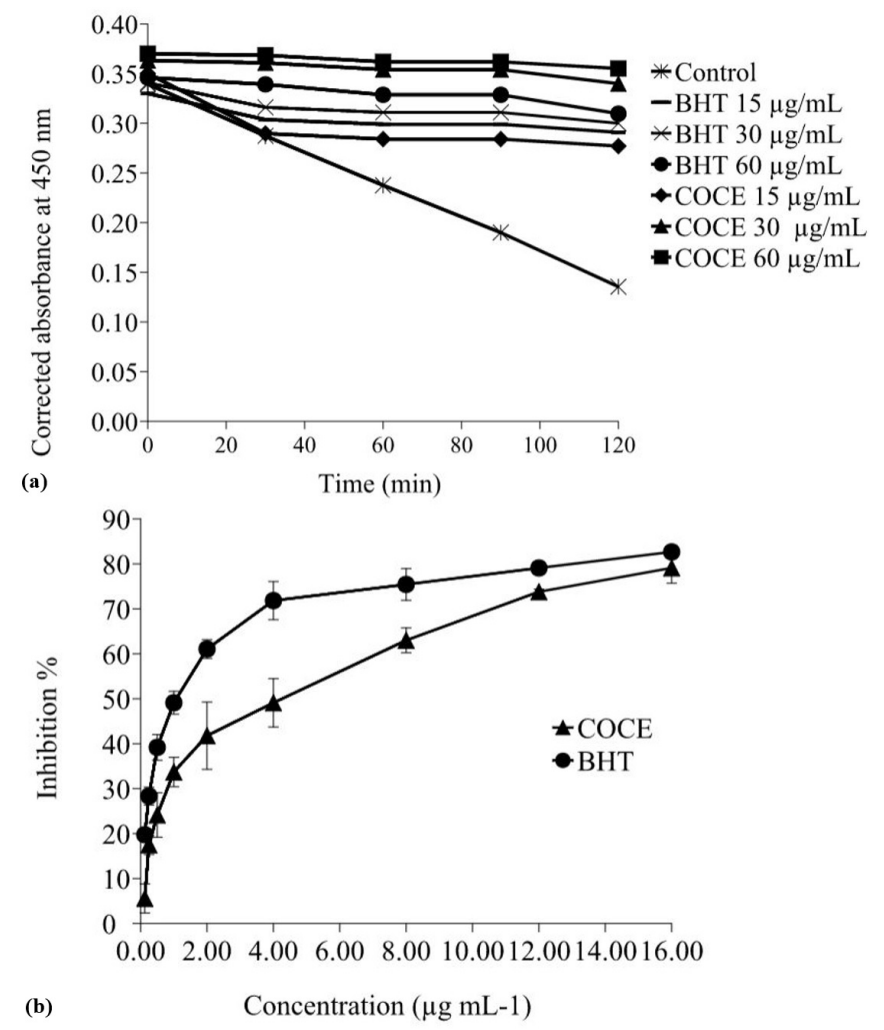

Figure 1. Antioxidant activities of coconut oil cake extracts (COCE). (a) Effect of BHT and COCE on $\beta$-carotene bleaching in linoleic acid emulsion; (b) Inhibition of TBRAS formation by BHT and COCE in egg yolk homogenates. respectively while that of methanol and ethyl acetate extracts of Mangifera indica, leaves at $10 \mathrm{mg} \mathrm{L}^{-1}$ concentration in the egg yolk homogenate system is $56.87 \pm 2.34$ and $68.27 \pm 3.12$ respectively (Badmus et al., 2011).

\subsection{Lipid peroxidation in cooked pork}

Pork has been used successfully as a food model for the evaluation of the effectiveness of plant-derived antioxidants against the deterioration of lipids. Inhibition of the formation of TBARS can be monitored during storage. Borage (Borago officinalis L.) meal showed concentration-dependent inhibition of the formation of TBARS at $2 \%(\mathrm{w} / \mathrm{w})$ and it inhibited TBARS formation by $26.5 \%$. Borage extracts at $200 \mathrm{ppm}$ concentration inhibited TBARS formation by $88 \%$ in cooked pork on 7 day storage at $4{ }^{\circ} \mathrm{C}$ (Wettasinghe \& Shahidi, 1999). In the present work, the antioxidant activity of COCE at $200 \mu \mathrm{g} / \mathrm{g}$ meat concentration was compared with that of synthetic food antioxidants BHT and TBHQ by monitoring the formation TBARS. Both synthetic antioxidants (BHT and TBHQ) and COCE inhibited the formation of TBARS in pork at all concentrations tested (Table 2). During the storage, all meat samples showed increasing concentrations of TBARS as a result of lipid oxidation. All the additives significantly lower TBARS values than the control over the entire storage period. It is important to notice that the TBARS value of the control sample with no added antioxidant is higher even at the day 0 , indicating that there is quick deterioration of meat with no added antioxidants even during the first few hours. High initial TBARS values of the cooked pork samples at day 0 is in accordance with the results reported by Chandrasekara \& Shahidi (2011).

\subsection{Thermal stability of antioxidants}

Thermal stability is an important parameter to be considered in evaluating the effectiveness of antioxidants in food systems. Most of the bakery and processed-food industries require the addition of antioxidants to food in order to protect food from deterioration during processing and storage. Loss of antioxidants at high temperatures is due to both evaporation and decomposition of antioxidants. Thermal decomposition products of $\mathrm{BHT}$, BHA and TBHQ have been investigated by gas chromatography (Hamama \& Nawar, 1991). The stability of four synthetic phenolic antioxidants at $185^{\circ} \mathrm{C}$ as detected by TLC and gas chromatography is in the order $\mathrm{BHT}>\mathrm{PG}>\mathrm{BHA}>\mathrm{TBHQ}$. However, according to another study, among synthetic antioxidants such as BHT,

Table 2. Variation of TBARS contents in pork treated with coconut oil cake extracts (COCE) and synthetic antioxidants.

\begin{tabular}{ccccc}
\hline \multirow{2}{*}{$\begin{array}{c}\text { Storage } \\
\text { time } \\
\text { (days) }\end{array}$} & Control & COCE $^{\star}$ & BHT* & TBHQ $^{\star}$ \\
\cline { 2 - 5 } & $16.71 \pm 2.26^{\mathrm{a}}$ & $1.77 \pm 0.15^{\mathrm{b}}$ & $0.98 \pm 0.08^{\mathrm{c}}$ & $0.91 \pm 0.08^{\mathrm{c}}$ \\
0 & $18.35 \pm 3.54^{\mathrm{a}}$ & $1.43 \pm 0.09^{\mathrm{b}}$ & $0.86 \pm 0.15^{\mathrm{c}}$ & $0.98 \pm 0.18^{\mathrm{c}}$ \\
5 & $18.91 \pm 2.90^{\mathrm{a}}$ & $1.44 \pm 0.10^{\mathrm{b}}$ & $1.29 \pm 0.28^{\mathrm{b}}$ & $1.78 \pm 0.14^{\mathrm{c}}$ \\
7 & $22.55 \pm 2.30^{\mathrm{a}}$ & $2.70 \pm 0.57^{\mathrm{b}}$ & $1.93 \pm 0.22^{\mathrm{b}}$ & $1.98 \pm 0.54^{\mathrm{b}}$ \\
\hline
\end{tabular}

*Antioxidant concentration: $200 \mu \mathrm{g} / \mathrm{g}$ meat. Data are expressed as means $\pm \mathrm{SD}(\mathrm{n}=3)$. Different letters $(a, b, c)$ in the same row indicates statistically significant $(\mathrm{p} \leq 0.05)$. 
BHA, TBHQ and ethoxyquin (EQ), the thermal inactivation is lowest for TBHQ as measured by Rancimat assay using sardine oil. In this system, the inactivation percentage of antioxidants after heat-treatment of antioxidants at $200{ }^{\circ} \mathrm{C}$ for $1 \mathrm{~h}$ vary in the order TBHQ $<$ BHT $<$ BHA $<$ EQ (Sanhueza et al., 2000). Variation of the inhibition of TBARS formation in egg yolk homogenates by heat-treated antioxidants with heating time is given in Figure 2a. Percentage inhibition of TBARS formation by BHT, BHA, TBHQ and COCE decrease with the heating time at $180^{\circ} \mathrm{C}$. However, COCE and TBHQ display reasonably higher activity at 30-90 min heating times compared to BHA and BHT.

Rancimat test was conducted to determine oxidation induction time of phenol-stripped sunflower oil after incorporating antioxidants,
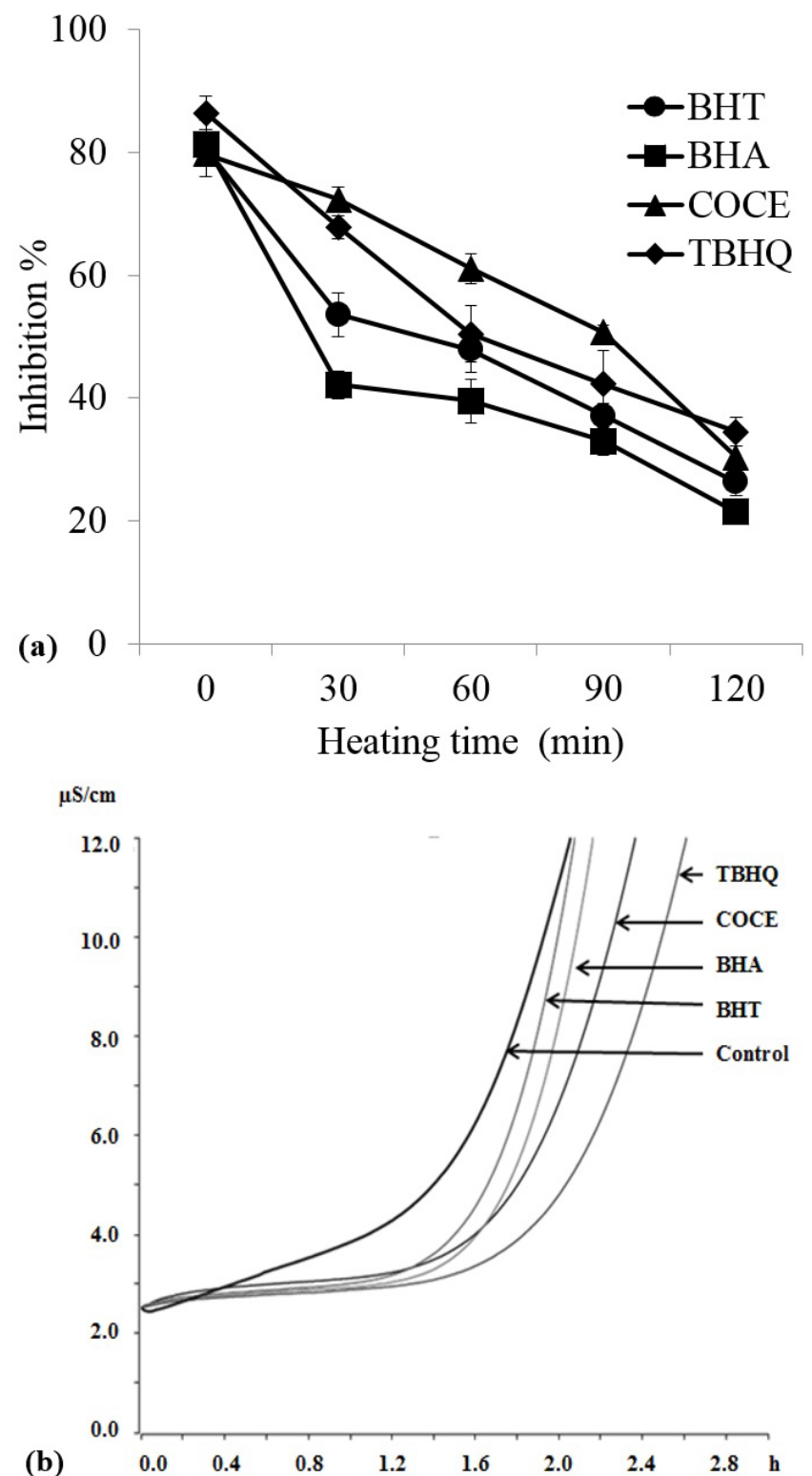

Figure 2. Thermal stability of coconut oil cake extracts (COCE). (a) Inhibition of TBRAS formation in egg yolk homogenates by heat-treated antioxidants; (b) Effect of heat-treated antioxidants on the oxidation induction time of sunflower oil. which were heat-treated at $180^{\circ} \mathrm{C}$ for two hours. Figure $2 \mathrm{~b}$ shows the effect of heat-treated antioxidants on the oxidation induction time of sunflower oil. Both inhibition of TBARS formation in egg yolk homogenates and induction time by Rancimat test indicate that TBHQ has the highest activity after heat-treatment followed by COCE. The protection factors for BHA, BHT, COCE and TBHQ calculated by assuming that the protection factor of the control as zero are $1.15 \pm 0.03,1.11 \pm 0.04,1.18 \pm 0.02$ and $1.32 \pm 0.05$ respectively. Even though the thermal stability of the antioxidants varies in the order $\mathrm{BHT}>\mathrm{PG}>\mathrm{BHA}>\mathrm{TBHQ}$ at $185^{\circ} \mathrm{C}$ according to the values reported by Hamama \& Nawar (1991), our results and the results reported by Sanhueza et al. (2000) indicate that the thermal stability variation and the antioxidant activity variation are not correlating, suggesting that even the thermally modified products of the antioxidants may still be active as antioxidants as the phenolic structures of most of them remain intact.

\subsection{Identification of phenolic compounds in COCE}

HPLC chromatogram of COCE is given in Figure 3. A major portion of the signals in the chromatogram were identified as either phenolic acids or flavonoids. The quantities of the identified phenolic substances ( $\mathrm{mg} / \mathrm{kg} \mathrm{COC}$ ) are gallic acid (23.0 \pm 5.9$)$, catechin $(26.9 \pm 6.4)$, chlorogenic acid (240.8 \pm 5.4$)$, p-hydroxy benzoic acid (129.0 \pm 6.8$)$, caffeic acid (225.7 \pm 82.2$)$, syringic acid (3.6 \pm 0.5$)$, ferulic acid (13.8 \pm 2.1$)$, $p$-coumaric acid $(6.2 \pm 0.5)$, elagic acid $(3.8 \pm 0.2)$ and apigenin $(56.7 \pm 9.8)$. Phenolic substances with ortho-diphenyl functionalities are known to be highly effective as antioxidants, as they can efficiently donate a hydrogen radical from a phenolic group to the substrate to neutralize substrate radicals. Then the resultant phenoxy radical can be stabilized by forming a cyclic intermediate with intramolecular hydrogen bonding with the ortho-phenyl group (Visioli \& Galli, 1998). Among the identified phenolic substances in COCE, gallic acid, catechin, chlorogenic acid, caffeic acid and elagic acid are orthophenols. They cover about $70 \%$ of the total

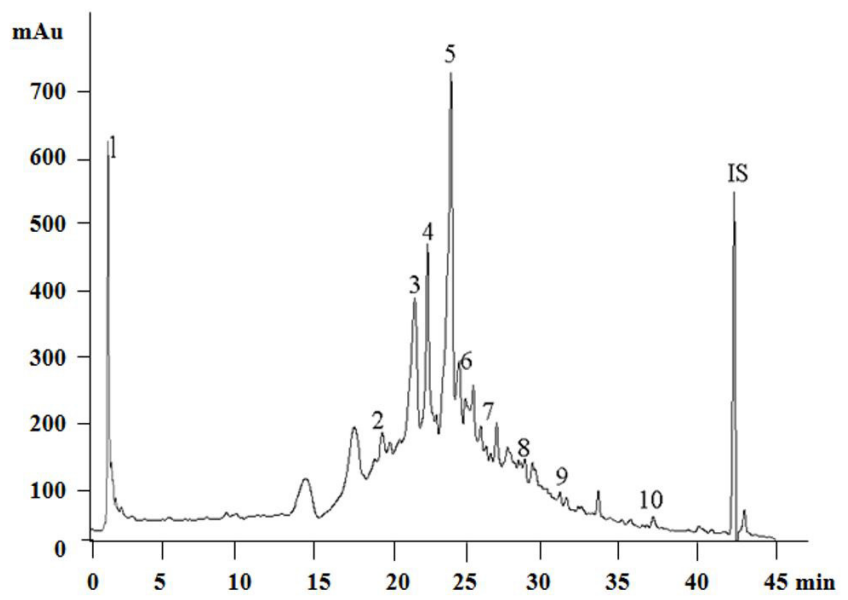

Figure 3. HPLC chromatogram of the phenolic fraction of COC: peak numbers (1) gallic acid; (2) catechin; (3) chlorogenic acid; (4) $p$-hydroxyl benzoic acid; (5) caffeic acid; (6) syringic acid; (7) ferulic acid; (8) p-coumaric acid; (9) elagic acid; (10) apigenin and IS - internal standard- galangin. 
weight and $63 \%$ of mole composition of the identified phenolic compounds. Therefore, the presence of a high percentage of thermally stable ortho diphenols as effective radical scavengers can be attributed to the antioxidant potential of COCE.

\section{Conclusion}

COCE can be effectively used to inhibit lipid peroxidation in various food systems. COCE can also retain the antioxidant activity at high temperatures as reflected by high inhibition percentage of TBARS formation in egg yolk homogenates and protection factor determined by Racimat apparatus using sunflower oil. These findings suggest that COCE may be used as a successful alternative for synthetic antioxidants in preserving food.

\section{Acknowledgements}

The financial support from the World Bank under HETC QIG Window 3 grant, National Research Council, Sri Lanka (Grant 12-012) and University of Kelaniya is highly appreciated.

\section{References}

Andrade, R. A. M. D. S., Maciel, M. I. S., Santos, A. M. P., \& Melo, E. D. A. (2015). Optimization of the extraction process of polyphenols from cashew apple agro-industrial residues. Food Science and Technology, 35(2), 354-360.

Badmus, J. A., Adedosu, T. O., Fatoki, J. O., Adegbite, V. A., Adaramoye, O. A., \& Odunola, A. O. (2011). Lipid peroxidation inhibition and antiradical activities of some leaf fractions of Mangifera indica. Acta Poloniae Pharmaceutica-Drug Research, 68(1), 23-29. PMid:21485698.

Casarotti, S. N., \& Jorge, N. (2014). Antioxidant activity of rosemary extract in soybean oil under thermoxidation. Journal of Food Processing and Preservation, 38(1), 136-145. http://dx.doi.org/10.1111/j.17454549.2012.00755.x.

Chandrasekara, N., \& Shahidi, F. (2011). Antioxidative potential of cashew phenolics in food and biological model systems as affected by roasting. Food Chemistry, 129(4), 1388-1396. http://dx.doi. org/10.1016/j.foodchem.2011.05.075.

Che Man, Y. B., \& Jaswir, I. (2000). Effect of rosemary and sage extracts on frying performance of refined, bleached and deodorized (RBD) palm olein during deep-fat frying. Food Chemistry, 69(3), 301-307. http://dx.doi.org/10.1016/S0308-8146(99)00270-8.

Daker, M., Abdullah, N., Vikineswary, S., Goh, P. C., \& Kuppusamy, U. R. (2008). Antioxidant from maize and maize fermented by Marasmiellus sp. as stabilizer of lipid-rich foods. Food Chemistry, 107(3), 1092-1098.

Hamama, A. A., \& Nawar, W. W. (1991). Thermal decomposition of some phenolic antioxidants. Journal of Agricultural and Food Chemistry, 39(6), 1063-1069. http://dx.doi.org/10.1021/jf00006a012.

Hatano, T., Kagawa, H., Yasuhara, T., \& Okuda, T. (1988). Two new flavonoids and other constituents in licorice root: their relative astringency and radical-scavenging effects. Chemical \& Pharmaceutical Bulletin, 36(6), 2090-2097. http://dx.doi.org/10.1248/cpb.36.2090. PMid:3240445.

Ito, N., \& Hirose, M. (1989). Antioxidants- carcinogenic and chemopreventive properties. Advances in Cancer Research, 53, 247-302. http://dx.doi. org/10.1016/S0065-230X(08)60283-3. PMid:2678948.

Ito, N., Fukushima, S., \& Tsuda, H. (1985). Carcinogenicity and modification of carcinogenic response by BHA, BHT and other antioxidants. CRC Critical Reviews in Toxicology, 15(2), 109-150. http://dx.doi.org/10.3109/10408448509029322. PMid:3899519.

Jaswir, I., Man, Y. B. C., \& Kitts, D. D. (2000). Synergistic effects of rosemary, sage, and citric acid on fatty acid retention of palm olein During Deep-fat Frying. Journal of the American Oil Chemists Society, 77(5), 527-533. http://dx.doi.org/10.1007/s11746-000-0084-7.

Kuppusamy, U. R., Indran, M., \& Balraj, B. R. S. (2002). Antioxidant effect of local fruits and vegetable extracts. Journal of Tropical Medicinal Plants, 3, 47-52.

Montedoro, G. F., Servili, M., Baldioli, M., \& Miniati, E. (1992). Simple and hydrolysable phenolic compounds in virgin olive oil.1. Their extraction, separation, and quantitative and semiquantitative evaluation by HPLC. Journal of Agricultural and Food Chemistry, 40(9), 1571-1576. http://dx.doi.org/10.1021/jf00021a019.

Perry, N. B., Burgess, E. J., \& Glennie, V. I. (2001). Echinacea standardization: analytical methods for phenolic compounds and typical levels in medicinal species. Journal of Agricultural and Food Chemistry, 49(4), 1702-1706. http://dx.doi.org/10.1021/jf001331y. PMid:11308313.

Ramachandran, S., Patel, A. K., Nampoothiri, K. M., Francis, F., Nagy, V., Szakacs, G., \& Pandey, A. (2004). Coconut oil cake-a potential raw material for the production of a-amylase. Bioresource Technology, 93(2), 169-174. http://dx.doi.org/10.1016/j.biortech.2003.10.021. PMid:15051078.

Reda, S. Y. (2011). Evaluation of antioxidants stability by thermal analysis and its protective effect in heated edible vegetable oil. Ciência e Tecnologia de Alimentos, 31(2), 475-480. http://dx.doi. org/10.1590/S0101-20612011000200030.

Roidoung, S., Dolan, K. D., \& Siddiq, M. (2016). Gallic acid as a protective antioxidant against anthocyanin degradation and color loss in vitamin-C fortified cranberry juice. Food Chemistry, 210, 422-427. http://dx.doi.org/10.1016/j.foodchem.2016.04.133. PMid:27211666.

Sanhueza, J., Nieto, S., \& Valenzuela, A. (2000). Thermal stability of some commercial synthetic antioxidants. Journal of the American Oil Chemists' Society, 77(9), 933-936. http://dx.doi.org/10.1007/ s11746-000-0147-9.

Seneviratne, K. N., \& Dissanayake, D. M. S. (2008). Variation of phenolic content in coconut oil extracted by two conventional methods. International Journal of Food Science \& Technology, 43(4), 597-602. http://dx.doi.org/10.1111/j.1365-2621.2006.01493.x.

Seneviratne, K. N., \& Kotuwegedara, R. T. (2009). Canarium zeylanicum seed oil: an edible oil with beneficial qualities. International Journal of Food Science \& Technology, 44(4), 792-798. http://dx.doi. org/10.1111/j.1365-2621.2008.01900.x.

Seneviratne, K. N., Hapuarachchi, C. D., \& Ekanayake, S. (2009). Comparison of the phenolic-dependent antioxidant properties of coconut oil extracted under cold and hot conditions. Food Chemistry, 114(4), 1444-1449. http://dx.doi.org/10.1016/j.foodchem.2008.11.038.

Siu, G. M., \& Draper, H. H. (1978). A survey of the malonaldehyde content of retail meats and fish. Journal of Food Science, 43(4), 1147-1149. http://dx.doi.org/10.1111/j.1365-2621.1978.tb15256.x.

Thamavit, W., Fukushima, S., Kurata, Y., Asamoto, M., \& Ito, N. (1989). Dose-dependent effects of butylated hydroxyanisole, butylated hydroxytoluene and ethoxyquin in induction of foci of rat liver cells containing the placental form glutathione S-transferase. Cancer Letters, 45(2), 93-101. http://dx.doi.org/10.1016/0304-3835(89)90142-0. PMid:2471582.

Tyopponen, J. T., \& Hakkarainen, R. V. J. (1985). Thermal stability of vitamin E in barley. Acta Agriculturae Scandinaviea, 35, 136-138.

United States Department of Agriculture - USDA. (2015). Oil seeds world market and trade (pp. 7). Washington: USDA. 
Visioli, F., \& Galli, C. (1998). Olive oil phenols and their potential effects on human health. Journal of Agricultural and Food Chemistry, 46(10), 4292-4296. http://dx.doi.org/10.1021/jf980049c.

Wettasinghe, M., \& Shahidi, F. (1999). Antioxidant and free radicalscavenging properties of ethanolic extracts of defatted borage (Borago officinalis L.) seeds. Food Chemistry, 67(4), 399-414. http://dx.doi. org/10.1016/S0308-8146(99)00137-5.

Wijeratne, S. S. K., Amarowicz, R., \& Shahidi, F. (2006). Antioxidant activity of almonds and their by-products in food model systems. Journal of the American Oil Chemists' Society, 83(3), 223-230. http:// dx.doi.org/10.1007/s11746-006-1197-8.
World Health Organization - WHO. Food and Agriculture Organization of the United Nations - FAO. Codex Alimentarius. (2001). Fats, oils and related products ( $2 \mathrm{nd}$ ed.). Geneva: WHO.

Wyatt, C. J., Carballido, S. P., \& Méndez, R. O. (1998). $\alpha$ - and $\gamma$-Tocopherol content of selected foods in the Mexican diet: effect of cooking losses. Journal of Agricultural and Food Chemistry, 46(11), 46574661. http://dx.doi.org/10.1021/jf9800716.

Xu, B. J., \& Chang, S. K. (2007). A comparative study on phenolic profiles and antioxidant activities of legumes as affected by extraction solvents. Journal of Food Science, 72(2), S159-S166. http://dx.doi. org/10.1111/j.1750-3841.2006.00260.x. PMid:17995858. 